\title{
CONSERVACIÓN \\ Y RE-USO DE \\ LAS CASAS DEL \\ MOVIMIENTO \\ MODERNO: UN \\ ACERCAMIENTO A \\ AMÉRICA LATINA
}

LOUISE NOELLE UNIVERSIDAD NACIONAL AUTÓNOMA DE MÉXICO, CIUDADE DE MÉXICO, MÉXICO Licenciatura en historia del arte en la Universidad Iberoamericana, y maestría en la Facultad de Filosofía y Letras de la UNAM. Participó como editora en la revista Arquitectura/México entre 1976 y 1979, al tiempo que coordinaba el Grupo de Diseño "Práxis". En 1981 ingresó a estudiar al IIE, formando parte de él como investigadora a partir de 1983. Su labor académica se enfoca en la investigación de la arquitectura contemporánea de México. E-mail: noelle@unam.mx

DOI

http://dx.doi.org/10.11606/issn.1980-4466.v0iesp22p41-61 


\section{CONSERVACIÓN Y RE-USO DE LAS CASAS DEL MOVIMIENTO MODERNO: UN ACERCAMIENTO A AMÉRICA LATINA \\ LOUISE NOELLE}

\section{RESUMEN}

El tema de las casas del Movimiento Moderno resulta interesante y complejo, como mucho de lo concerniente a la arquitectura del siglo XX, tanto su apreciación, conservación, restauración y protección. Las casas por su condición privada, la ausencia de los dueños originales y el asedio inmobiliario ofrecen mayores problemas de preservación; por ello el tema del re-uso es inherente a este patrimonio. Este artículo propone enlazar con el tema de la habitabilidad y las diversas expresiones físicas de la casa, puesto que se trata de una tipología arquitectónica por excelencia, que ha sido el laboratorio ideal para los arquitectos que han experimentado con formas, materiales y técnicas, a la vez que han buscado respuestas a las nuevas ideas de privacidad, confort y relación con el clima y el entorno. Mucho se ha escrito sobre este tema, por lo que el texto se limita a un breve recorrido por algunas de las casas paradigmáticas de los Maestros europeos y norteamericanos, para enfatizar posteriormente lo que sucede en América Latina y particularmente en México. Asimismo se revisan los problemas del re-uso y la restauración, que debe quedar en manos de especialista siempre con la asesoría de los historiadores; finalmente se hace una recapitulación de los conceptos vertidos en algunas Cartas y Declaraciones internacionales.

\section{PALABRAS CLAVES}

Casas. Conservación. Re-uso. Legislación internacional. 


\title{
CONSERVAÇÃO E REÚSO DAS CASAS DO MOVIMENTO MODERNO: UM ENFOQUE NA AMÉRICA LATINA
}

\author{
LOUISE NOELLE
}

\section{RESUMO}

O tema "casas do movimento moderno" é interesante e complexo, tal como a prória arquitetura do século XX, seja pela sua identificação, conservação, restauração ou proteção. As casas, por sua condição privada, pela ausência dos proprietários originais e pelo interesse imobiliário, oferecem maiores problemas de preservação; por isso o tema de reúso é inerente a este patrimônio. Este artigo propõe debater o tema habitabilidade e as diversas expressões físicas da casa, posto que se trata de uma tipologia arquitetônica por excelência que tem sido o laboratório ideal para os arquitetos que realizam experiências com formas, materiais e técnicas, na busca de respostas para novas ideas de privacidade, conforto e sua relação com o clima e o entorno. Muito se tem escrito sobre este tema, por isso o texto se limita a um breve percurso por algumas casas paradigmáticas de mestres europeus e norte-americanos para enfatizar posteriormente o que acontece na América Latina, particularmente no México. Também se revisam os problemas do reuso e da restauração, que devem ficar nas mãos de especialistas, sempre com a assesoria de historiadores; finalmente faz-se uma recapitulação dos conceitos presentes em algumas cartas e declarações internacionais.

PALAVRAS-CHAVE:

Casas. Conservação. Reúso. Legislação internacional. 


\section{CONSIDERACIONES INICIALES}

Es posible aseverar que las casas paradigmáticas diseñadas por los maestros del Movimiento Moderno han venido enfrentando en este siglo muy variados desafíos. En este sentido, resulta necesario entender que su destino, incluyendo su adecuada conservación, está íntimamente ligada con el uso o re-uso que puedan tener en la actualidad. Así se convierten una propuesta atractiva y compleja, como mucho de la arquitectura del siglo XX, tanto en su apreciación, como en su conservación, restauración y protección.

A esto se aúna el hecho de que las casas, por su condición de obras privadas, tienen mayores problemas tanto en su defensa como en su preservación; por ello la idea del re-uso es inherente a este patrimonio, ya que en general estas casas fueron proyectadas para un cliente en particular quien, con el paso del tiempo, no vive más en ellas.

Casa e indústria passam, portanto, a ser tipologias reconhecidas como patrimônio cultural com interesse de preservação somente a partir do alargamento dessa compreensão, em consonância com a difusão das proposições da micro-história, das narrativas do cotidiano, uma experiência que se torna recorrente quando o homem comum passa a ser admitido como narrador.

Nesta mesa deu-se voz, de um lado, a uma habitante da casa operária associada à produção popular, ao universo do trabalho e do trabalhador. 
De outro, a dois habitantes de casas modernas não necessariamente identificadas com o senso comum de patrimônio, usualmente associado às formas e tipologias tradicionais. Ao relato daqueles que vivem em bens culturais, agregou-se a contribuição de um agente imobiliário que inclui em sua carteira de clientes os proprietários de bens tombados.

La casa es un género arquitectónico que ha sido capaz de integrar conceptos de vanguardia al tiempo que promover ideas novedosas, para lograr a lo largo del siglo XX excelentes ejemplos de creatividad. Por ello, al revisar los espacios domésticos, en ese siglo, es posible trazar su desarrollo y sus contribuciones a la arquitectura en general. En efecto, el tema de la habitabilidad y los variados aspectos físicos de las viviendas las convierten en la tipología arquitectónica por excelencia, lo que se aúnan las diversas formas de organización social a lo ancho de nuestro planeta.

La propuesta se enlaza desde las manifestaciones prehistóricas, recordemos aquí libros señeros como el de Joseph Rykwert, On Adams House in Paradise: the Idea of the Primitive Hut in Architectural History (RYKWERT, 1972), hasta los ejemplos contemporáneos, donde se muestran las diversas formas de organización social a lo ancho de mundo. Se puede agregar que desde el siglo XIX, pero particularmente en el XX, la casa habitación ha sido el laboratorio ideal para los arquitectos que han experimentado así con formas, materiales y técnicas, a la vez que han buscado respuestas a las nuevas ideas de privacidad, confort y relación con el clima y el entorno. Sin embargo, se debe agregar que a pesar de que la construcción de casas en ese periodo ha sido extensa y sugestiva, resulta asimismo muy difícil de mantener y conservar.

Un interesante antecedente sobre este tema, es el expuesto en la edición número 132 de la revista española A\&V, "Casas de Maestro" (LAPUERTA, 2009), donde José María de Lapuerta realiza un estudio sobre las casas paradigmáticas de los maestros de la arquitectura del Movimiento Moderno; ofrece diez capítulos sobre sendas casas, estudiando puntualmente su historia y su diseño. Además, se debe agregar que sobre este tema mucho se ha publicado, tanto en textos teóricos como en recuentos históricos sobre la habitabilidad; es el caso de obras como Dweling and Architecture. From Heidegger to Koolhas, de Pavlos Lefas, que no ofrece una visión del concepto de habitar en el último siglo. (LEFAS, 2009) 
En el caso particular que nos atañe de la arquitectura doméstica latinoamericana, y especialmente mexicana, la existencia de un folleto de Alberto T. Arai intitulado también "La casa mexicana. Ideas sobre la habitación popular urbana"', abre estos escritos. También es necesario recoger otras publicaciones sobre este tema fundamental para la arquitectura, como la serie Historia de la vida cotidiana en México (AIZPURU, 2006), dirigida por Pilar Gonzalbo Aizpuru, que de cierta forma se enlaza con la propuesta de Enrique Ayala Alonso en su libro La idea de habitar: La Ciudad de México $y$ sus casas 1750-1900 (2009), en donde hace un atinado recorrido sobre lo privado y su percepción, y la consiguiente evolución de la vivienda. Este se vincula con otros trabajos sobre el tema de las casas, en particular la tesis de doctorado de 2002, en proceso de edición, de Lourdes Cruz González Franco, "El espacio habitacional en México: La casa habitación unifamiliar en la ciudad de México durante el siglo XX".

En ese mismo sentido, existen dos publicaciones colombianas de interés para este tema, Pasados Presentes. La vivienda en Colombia, editada por Alberto Saldarriaga Roa (2009) y que propone una visión del desarrollo de la casa en ese país desde épocas precolombinas y el libro de Beatriz García Moreno, De la casa patriarcal a la casa nuclear (GARCÍA MORENO, 1995), con un acucioso estudio, en el que los levantamientos se acompañan de interesantes reflexiones.

En Brasil, Roberto Segre publicó Casas Brasileiras (SEGRE, 2010), haciendo referencia a buen número de residencias en ese país,; por su parte Marlene Milan Acayaba realizó una acuciosa publicación Residências em Sao Paulo: 1947-1975 (ACAYABA, 2011), que da cuenta de una excelente investigación sobre las casas modernas de esa ciudad.

Finalmente, con algunas otras publicaciones que no se han mencionado, coexisten un buen número de libros de difusión que no aportan a la discusión sobre el tema ya que se centran en las imágenes, así como otros que se ocupan de alguna casa o arquitecto en particular, lo que sería demasiado largo revisar para este breve ensayo

1. Alberto T. Arai, La casa mexicana. Ideas sobre la habitación popular urbana, $\mathrm{N}^{\circ} 2$, México, $\mathrm{SAM}$, s/f. Es la reproducción de una conferencia dictada el 5 de junio de 1956 y agradezco al arquitecto Raúl Díaz la copia de este folleto. 


\section{CASAS PARDIGMÁTICAS DE LOS GRANDES MAESTROS DEL MOVIMIENTO MODERNO}

De cierta forma es apropiado iniciar con algunas de las casas paradigmáticas de los maestros europeos y norteamericanos, para pasar a enfatizar posteriormente lo que sucede en nuestra América. En todo caso, resulta siempre fundamental centrar la discusión en el tema del uso actual, aparte de la enorme problemática de la restauración, que deberá de quedar en manos de especialistas siempre con la asesoría de los historiadores. Por una parte se deben recoger las casas que en la actualidad cuentan con la distinción de ser Patrimonio de la Humanidad, como las villas Savoye y La Roche-Jeanneret, las casas Curutchet y Guiette, las casas de la Weisenhoff de Suttgart y la pequeña casa del Lago Leman, así como el Cabanon de Le Corbusier, la Casa Tugendat de Ludwig Mies Van der Rohe, la Casa Schöder de Gerrit Rietveld (foto 1) o la Casa de Luis Barragán; por demás está señalar que en casi todos los casos se trata de edificaciones que fungen como museos en mayor o menor medida.También son de tomar en cuenta las casas Farnsworth de Ludwig Mies Van der Rohe, Falling Water y Talliessin West de Frank Lloyd Wright (foto 2), Lovell y Kaufmann de Richard Neutra, Eames de Charles y Ray Eames, Menlikov de Konstantin Menlikov, Aalto y Mairea de Alvar Aalto (foto 3), Prouvé de Jean Prouvé y la Casa de Cristal de Philip Johnson, entre muchos otros ejemplos significativos del Movimiento Moderno. La mayoría de estas se han conservado en buen estado y cuentan con diversos grados de protección.

\section{LATINOAMÉRICA}

Para América Latina la lista es larga, donde se puede iniciar con la recientemente declarada Casa Curutchet (1948), de Le Corbusier en La Plata, Argentina ${ }^{2}$. Asimismo, resulta interesante aquilatar aquellas viviendas que los arquitectos construyeron para sí mismos, ya que se pueden considerar como un legado de valor y una declaratoria de principios. Se puede discurrir así sobre la casa de Carlos Raúl Villanueva en Caoma, Caracas (foto 4), donde se localiza actualmente su archivo, la de Oscar Niemeyer en Canoas, Rio de Janeiro (foto 5), la Casa de Cristal de Lina Bo Bardi, todas construidas

2. Declarada en 2016. 
FIGURA 1

Gerrit Rietveld, Casa Schöder, Uthech,

Holanda. Foto:

Louise Noelle.

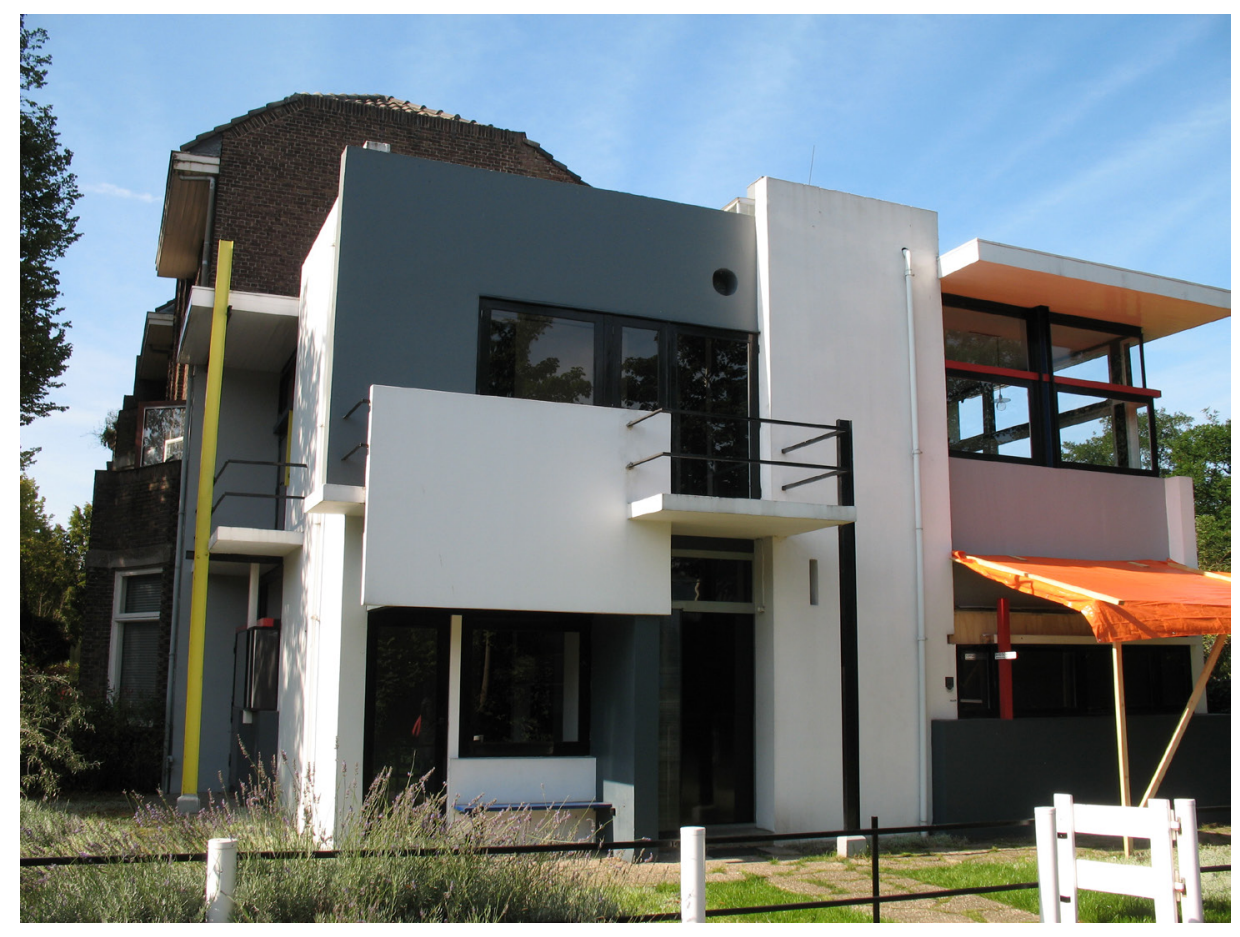

FIGURA 2

Frank Lloyd Wright,

Taliesin West,

Arizona.

Foto: Louise Noelle.

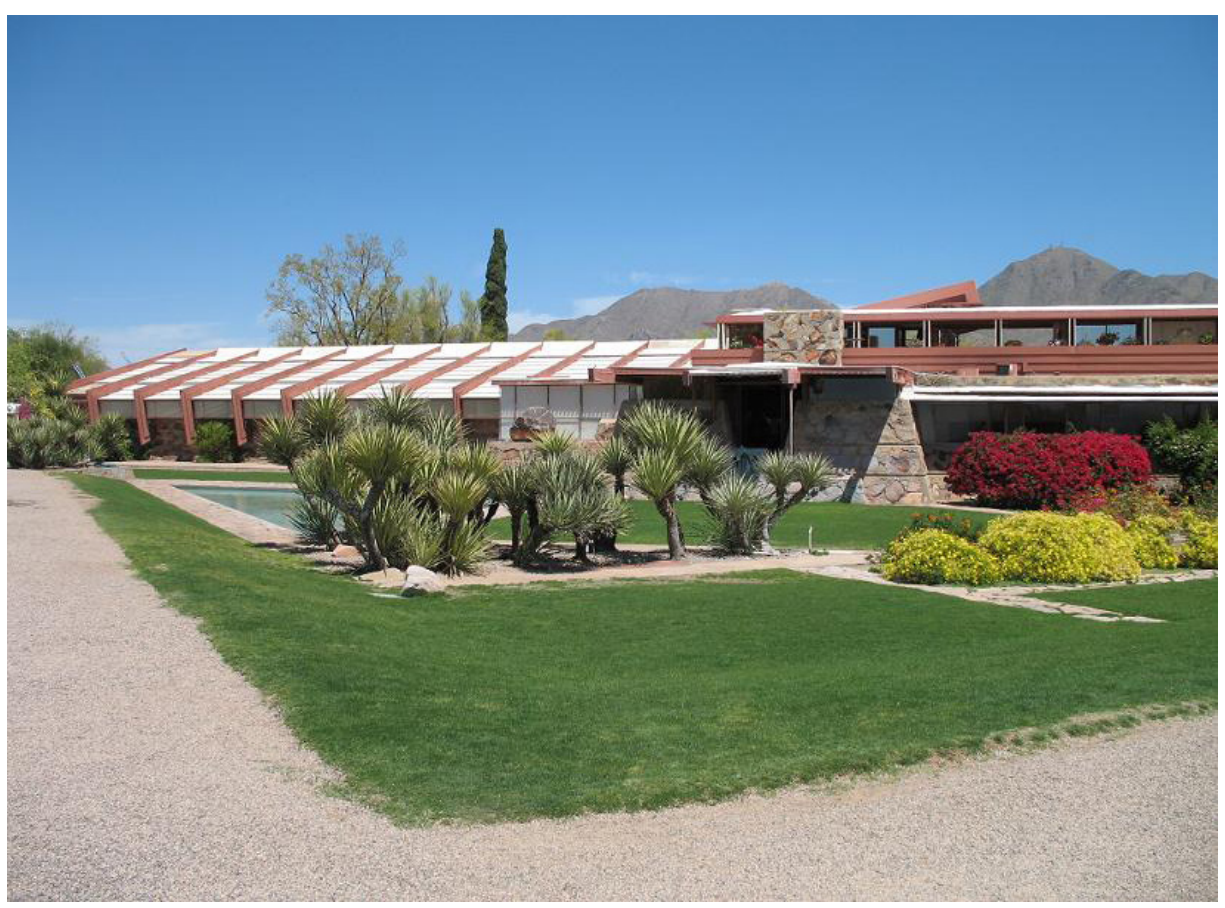




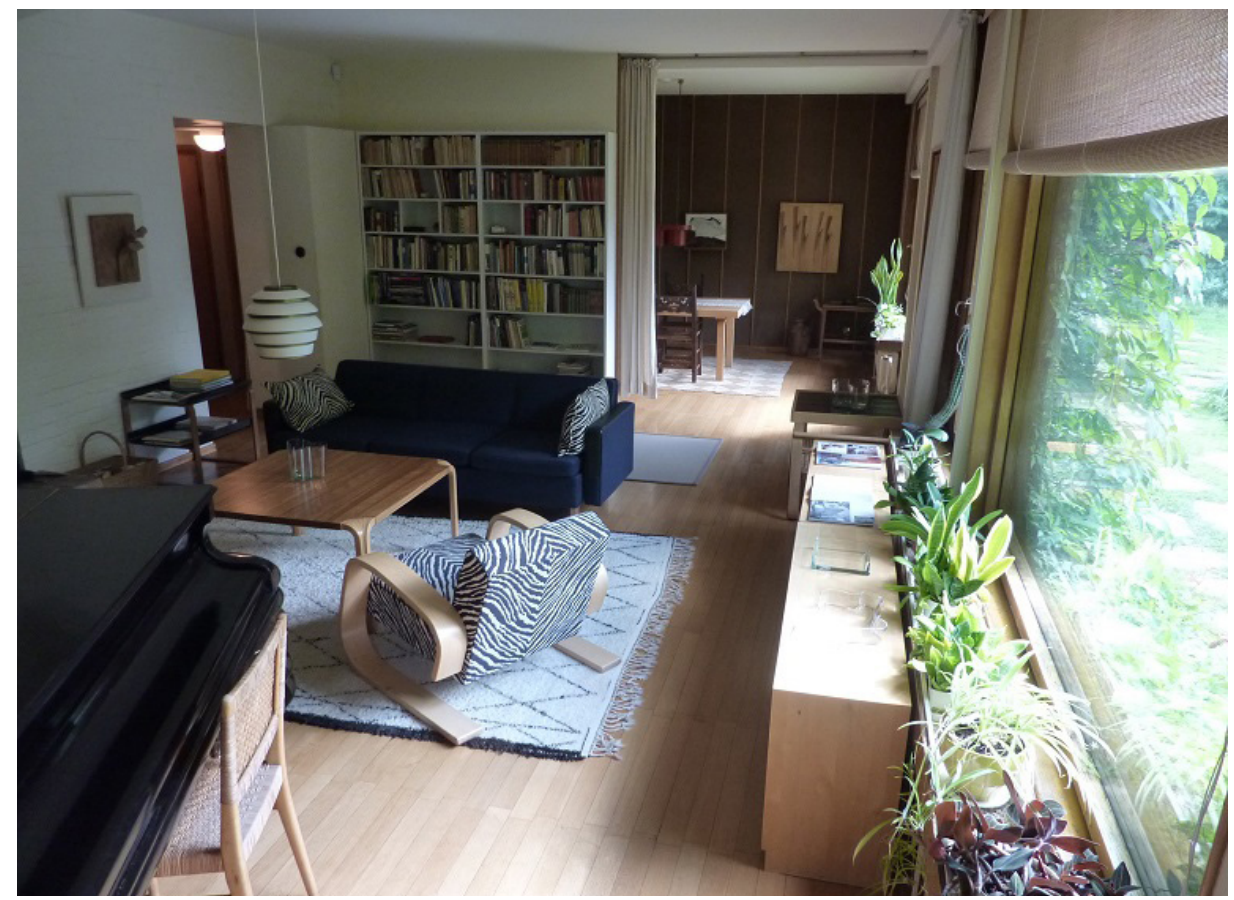

en 1951 y con una buena conservación; otros casos dignos de mencionar son El Tarantín (1955) de Fruto Vivas en Caracas, así como la casa (1961) de Eladio Dieste en Montevideo, ya que en ambos se puede apreciar un personal sistema constructivo perfeccionado por los autores; igualmente se debe considerar la casa (1962) de Segio Larrain GM, como una propuesta regionalista que forma parte de la Pontificia Universidad Católica, en Santiago, la casa (1960) de Guillermo Bermúdez en Bogotá que actualmente funciona como un restaurante, ambos ejemplos comprueban el amplio abanico del re-uso de viviendas reconocidas; en cuanto a las adecuaciones de Roberto Burle Marx en El Sitio (c.1950) (foto 6), para instalar su residencia y sus viveros, demuestran que el tema de la conservación de estas viviendas va más allá de la construcción, ya que es imperativo integrar la preservación de la decoración y el paisajismo.

Por otra parte, existen una gran cantidad de residencias que naturalmente debe encabezar Gregory Warchavchik con casas como la de Rua Itápolis (1930), como una de las pioneras del Movimiento Moderno en 


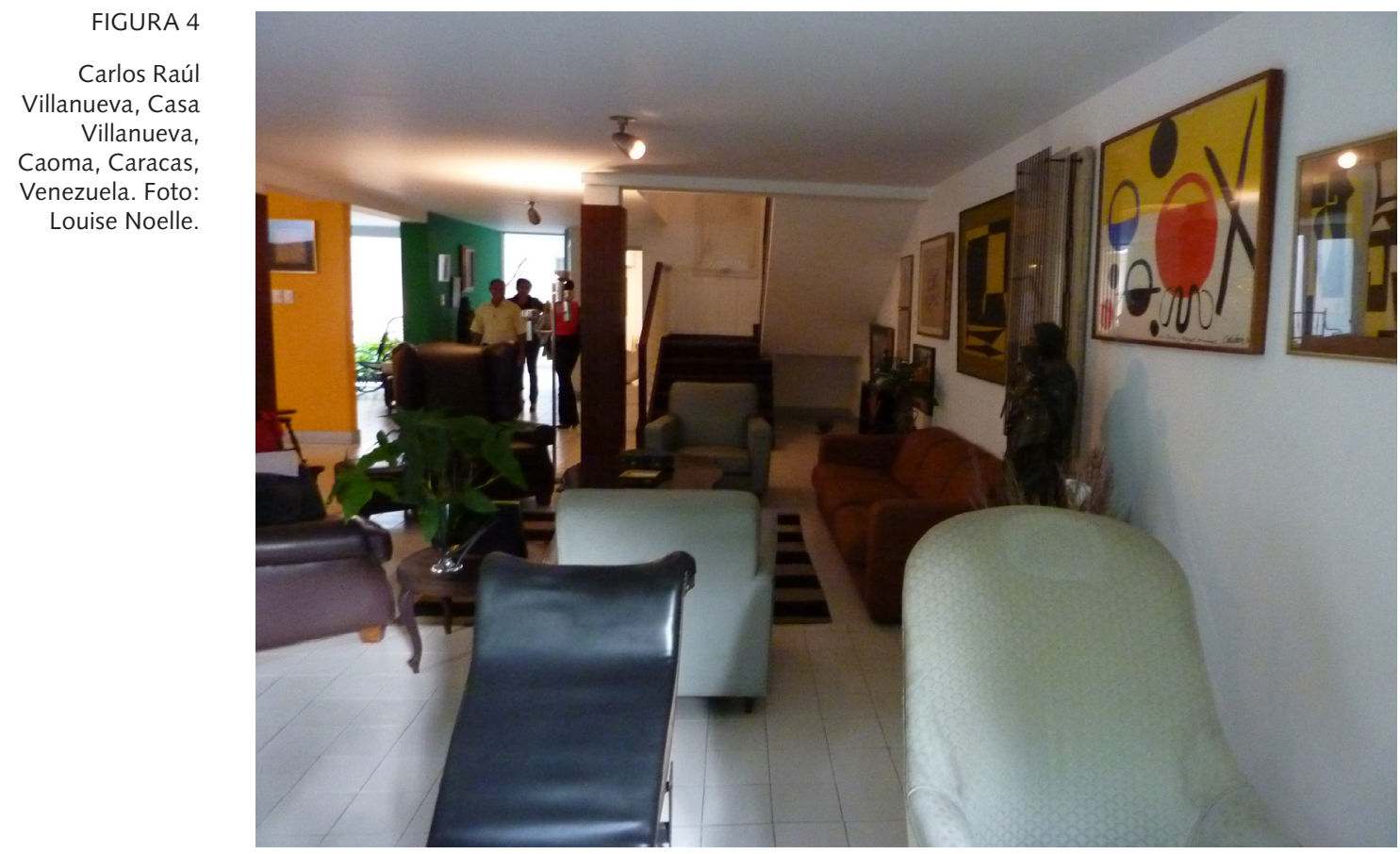

Brasil; también se debe tomar en cuenta la Villa Planchard (1957) de Gio Ponti, en Carácas (foto 7), por su trascendencia y el cuidado con que se ha conservado, mientras que el caso opuesto es el de la Casa sobre el arroyo (1945) de Amancio William en Mar del Plata, que ha sufrido graves daños. En todo caso, tanto la cabal supervivencia como el destino de estas obras destacadas, son muy variados, aunque parece haber una tendencia hacia transformarlas en espacios museísticos.

En cuanto a México y las casas de los arquitectos, es preciso abrir con Luis Barragán y su casa (1949-50) (foto 8), en la ciudad capital, ya que fue declarada Patrimonio de la Humanidad ${ }^{3}$, por lo que cuenta con una excelente conservación y la posibilidad de visitarla; desafortunadamente otros ejemplos fundamentales en la misma ciudad, se han perdido, como la trascendente casa de Enrique del Moral (1949), destruida por Fernando Romero (CURTIS, 1997), o la casa orgánica de Juan O'Gorman (1953-55),

3. En 2004. 


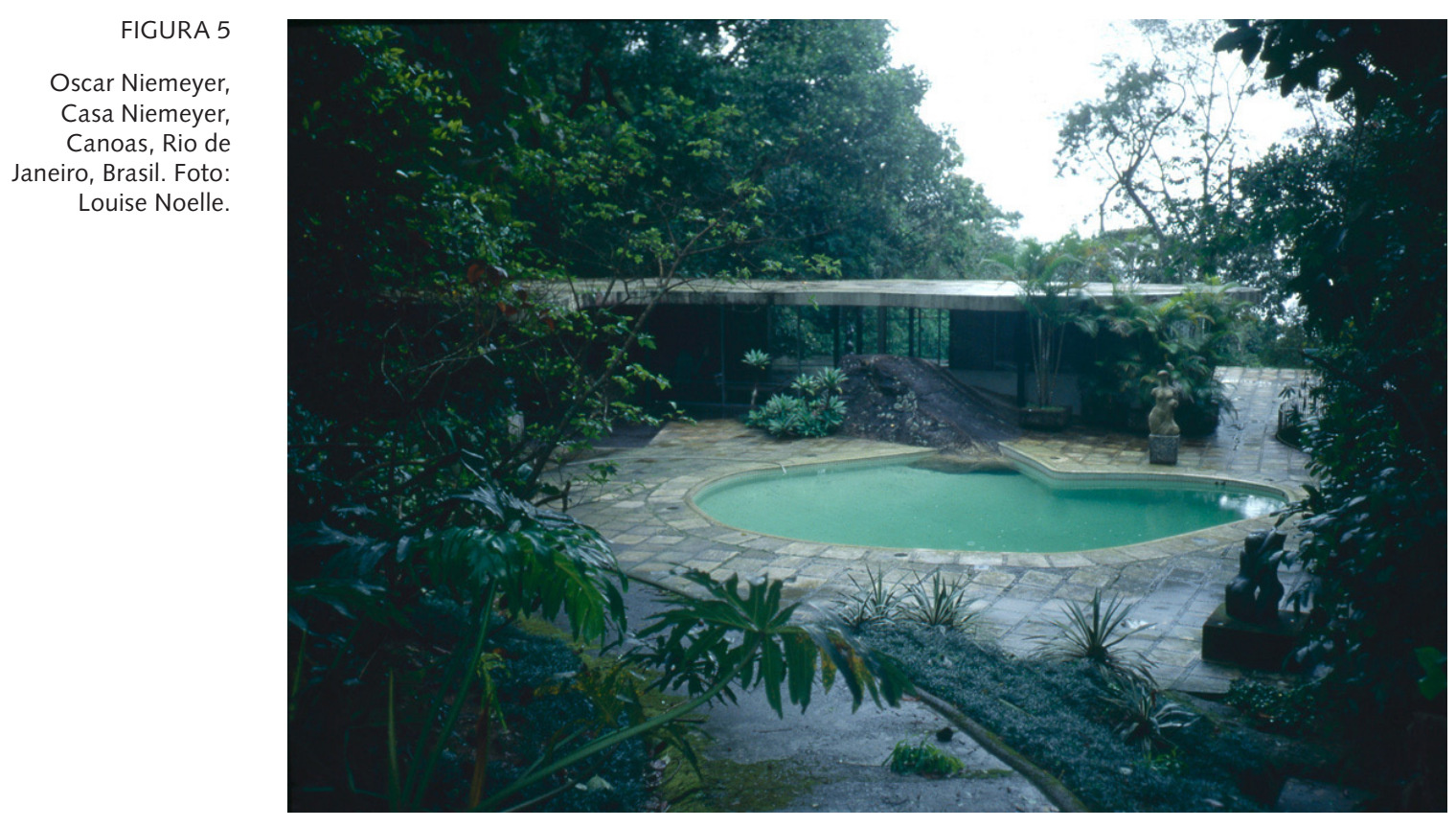

FIGURA 6

Roberto Burle Marx,

Jardines de El Sitio

Rio de Janeiro, Brasil.

Foto: Louise Noelle.

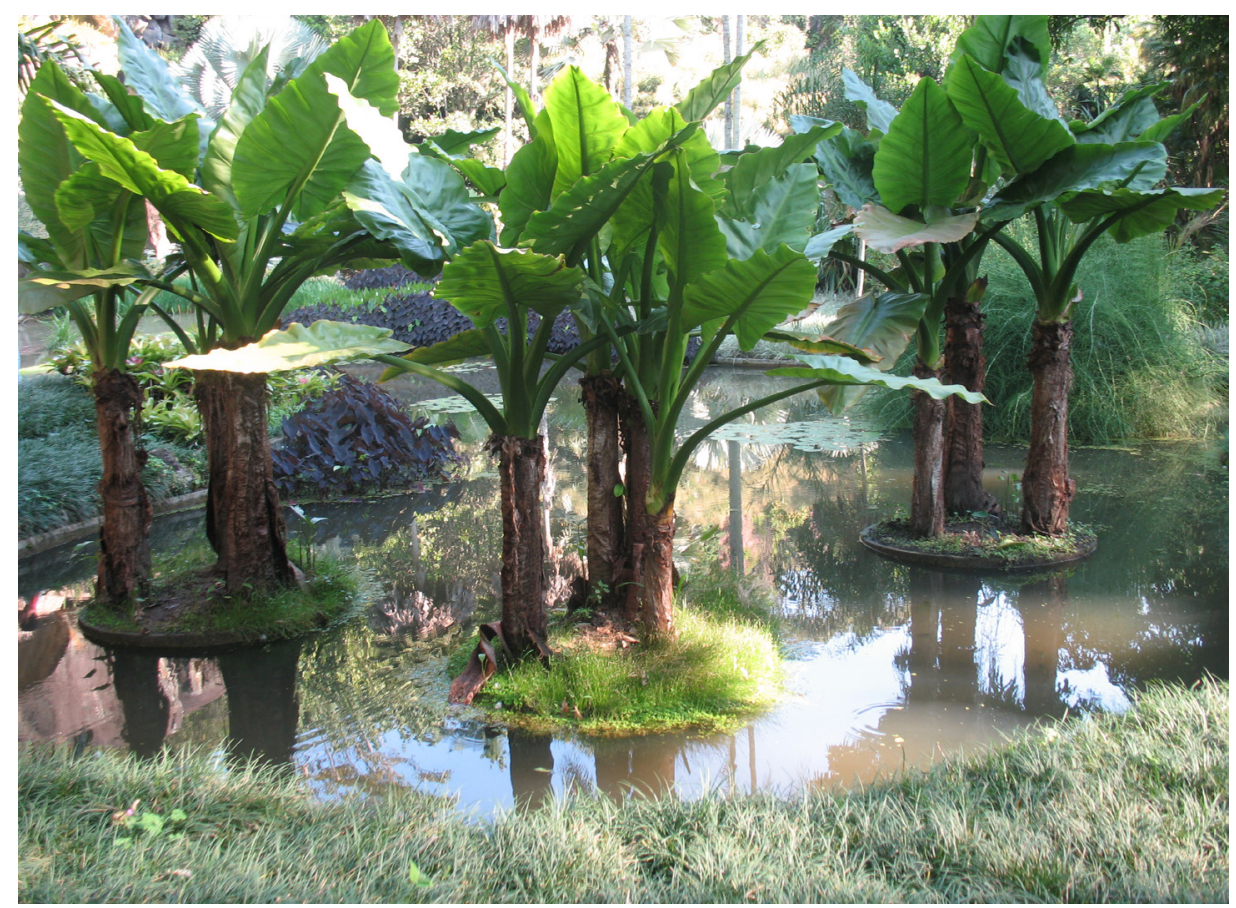




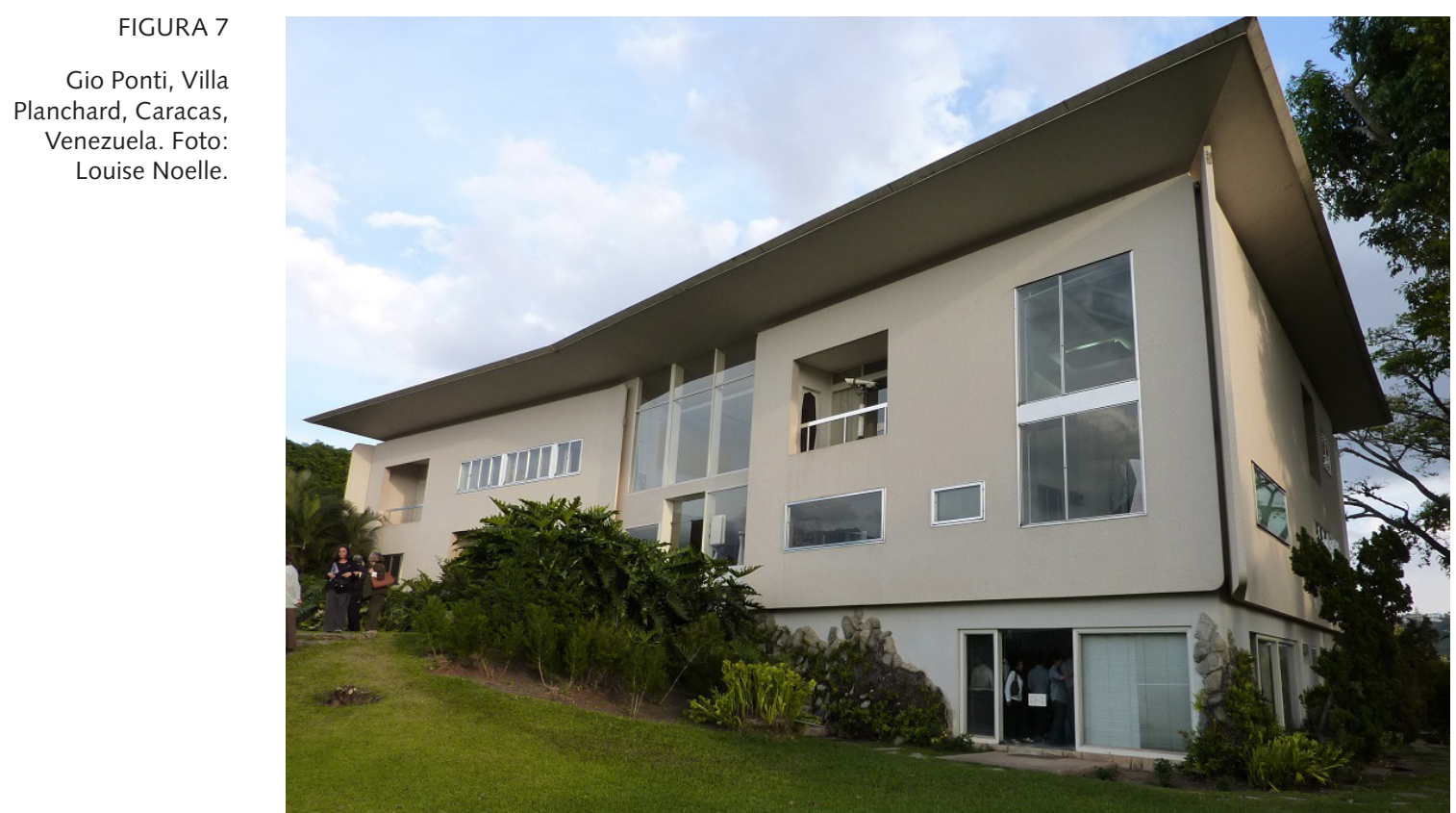

destruida por Helen Escobedo (foto 9), y que decir de la casa de Juan Sordo Madaleno, destruida por su hijo, Javier Sordo (O'GORMAN, 1976). Otras dos casas relevantes que se perdieron, son la de Mario Pani (1937) y la de Enrique Yáñez (1959), ante la codicia inmobiliaria. Dentro de los ejemplos que han logrado sobrevivir, está la casa de José Villagrán García (1935), pionero del Movimiento Moderno en México, la de Francisco J. Serrano (1933), que fue adecuada como restaurante, o la de Augusto H. Álvarez (1961), a pesar de haber sido subdividida en dos viviendas.

En cuanto a otras residencias relevantes en México, es preciso iniciar con Juan O'Gorman, y las Casa para Cecil O'Gorman (1930) y Casas para Diego Rivera y Frida Kahlo (1931) (fotos 10 e 11), por ser pioneras en México; desde hace un buen tiempo fueron restauradas con gran acierto y en la actualidad forman parte de un conjunto museal. También se deben señalar algunas de las obras iniciales de Barragán en Guadalajara que están bien mantenidas, como la Casa González Luna4 (1928) (foto 12) actualmente 
FIGURA 8

Luis Barragán, Casa

Barragán, Ciudad

de México, México.

Foto: Louise Noelle.

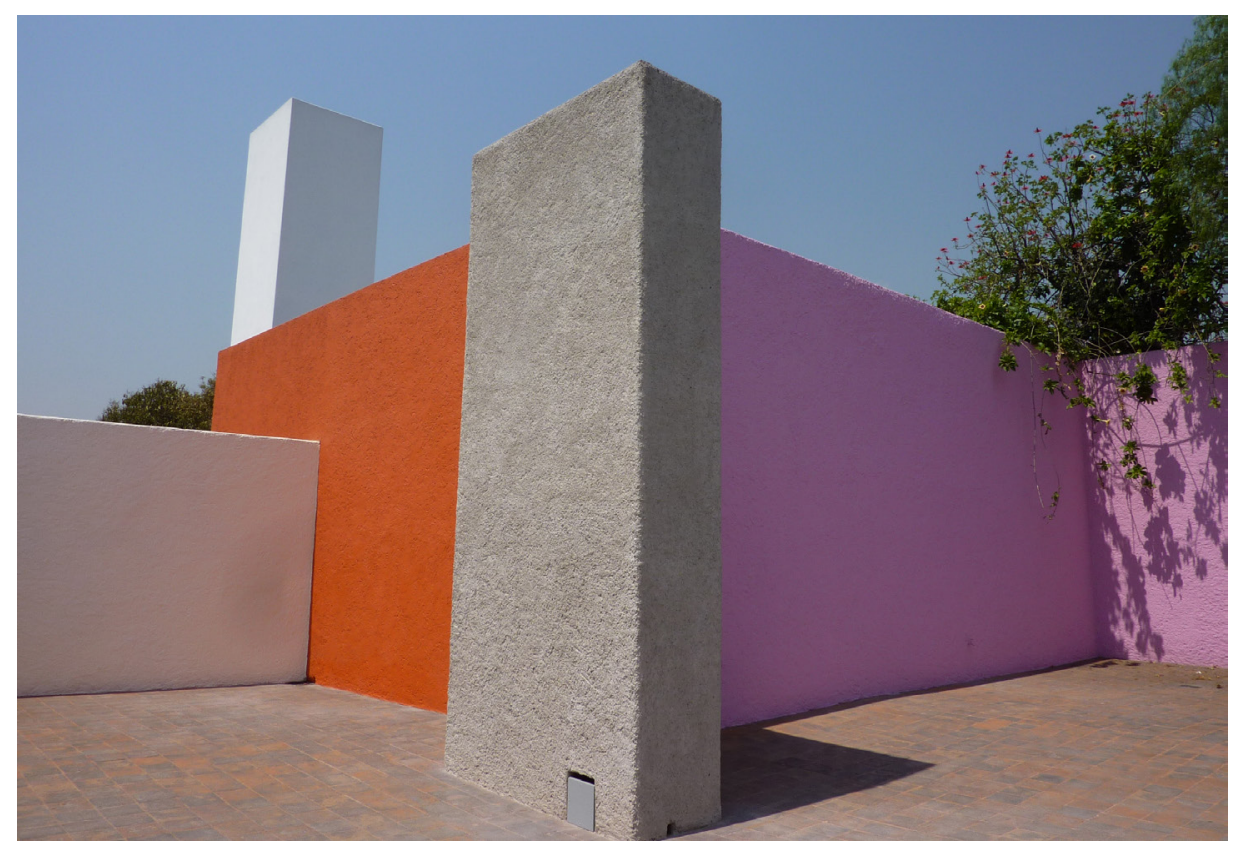

FIGURA 9

Juan O'Gorman,

Casa Fantástica,

Ciudad de México,

México. Foto: Juan

Guzmán, archivo

Louise Noelle.

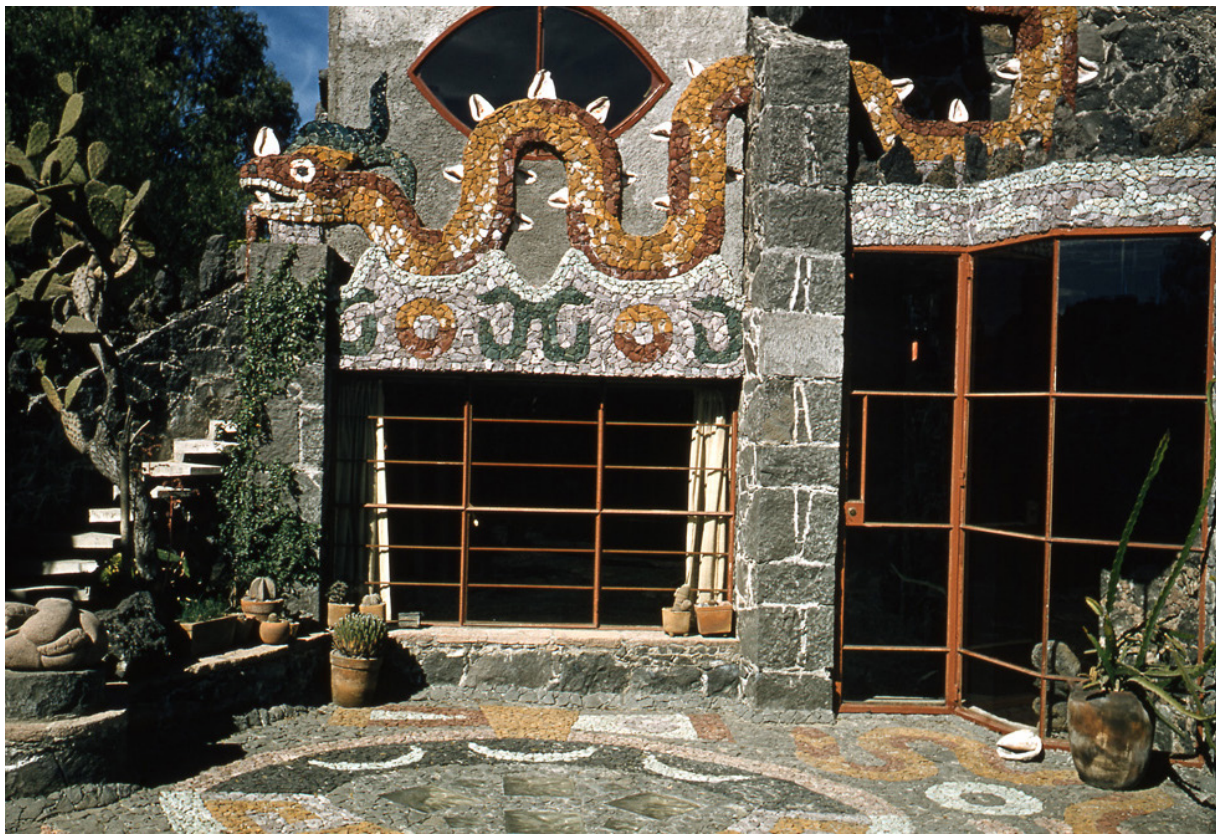


parte del Instituto Tecnológico de Estudios Superiores de Occidente y la Casa Gustavo Cristo (1929), que ocupa el Colegio de Arquitectos de Jalisco.

Una obra que resulta fundamental para este periodo inicial es la Casa para la familia Yturbe (1944), en Acapulco ${ }^{5}$, de Enrique del Moral, Casa en Acapulco, (foto 13) interesante tanto por ser una de las propuestas iniciales del regionalismo, como por personificar los textos que escribió sobre este tema; se trata de un diseño arquitectónico adaptado al trópico de la costa del Pacífico mexicano que propicia tempranas soluciones bio-climáticas, a la vez que incluye un interesante mobiliario de la diseñadora de origen cubano, Clara Porset (2006). Asimismo, dentro del tema de la conservación debemos recordar las lúcidas palabras de Del Moral: "Nuestro pasado es parte integral de lo que somos... por ello debemos conservar las expresiones culturales más representativas de ese pasado..." (MORAL, 1980)

En fechas recientes Barragán ha despertado interés, a lo que se aúna el buen estado de estas obras de su periodo de madurez, a pesar de no ser fácilmente visitables al permanecer como residencias. Por ello la reciente y acertada restauración de la Casa Prieto López (1950), (foto 14) toma una especial relevancia ${ }^{6}$; proyectada en el Pedregal de San Ángel, privilegió la idea de adaptarse a un terreno con desniveles y tomando en cuenta la fuerza de la piedra volcánica, además de proponer una experimentación estética y emocional. La residencia de Antonio Gálvez de 1955, con su organización fluida de los espacios, muestra una continuidad en su adecuada preservación, con un amplio jardín y la presencia de Clara Porset en los interiores. Finalmente es necesario mencionar aquí la buena conservación de las casas Egerstrom (1968), Gilardi (1976) y Meyer (1980).? Como se ha hecho mención, es fundamental destacar que la conservación de una casa, está ligada indefectiblemente con la preservación integral de interiores y exteriores. En este sentido, cobran particular relevancia los jardines diseñados por los

\footnotetext{
5. Enrique del Moral, "Arquitectura en Acapulco", Arquitectura/México, No 46, México, 1954; "Lo general y lo local”, Espacios, No. 2, México, 1948; y "Modernidad contra tradición, integración”, Arquitectura/México, No. 45, México, 1954. Louise Noelle, Enrique del Moral. Vida y obra, UNAM, México, 2004.

6. Adquirida en 2014 por César Cervantes, se dio a la tarea de recuperarla con los arquitectos Jorge Covarrubias y Benjamín González Henze, de Parque Humano, y la supervisión de la Dirección de Arquitectura y Patrimonio Artístico Inmueble de Bellas Artes.

7. Louise Noelle, Luis Barragán, búsqueda y creatividad, UNAM, México, 1996.
} 
FIGURA 10

Juan O'Gorman, Casa O'Gorman, Ciudad de México, México. Foto: Louise Noelle.

FIGURA 11 Juan O'Gorman Casas Diego Rivera y Frida Kahlo, Ciudad de México, México. Foto: Louise Noelle.
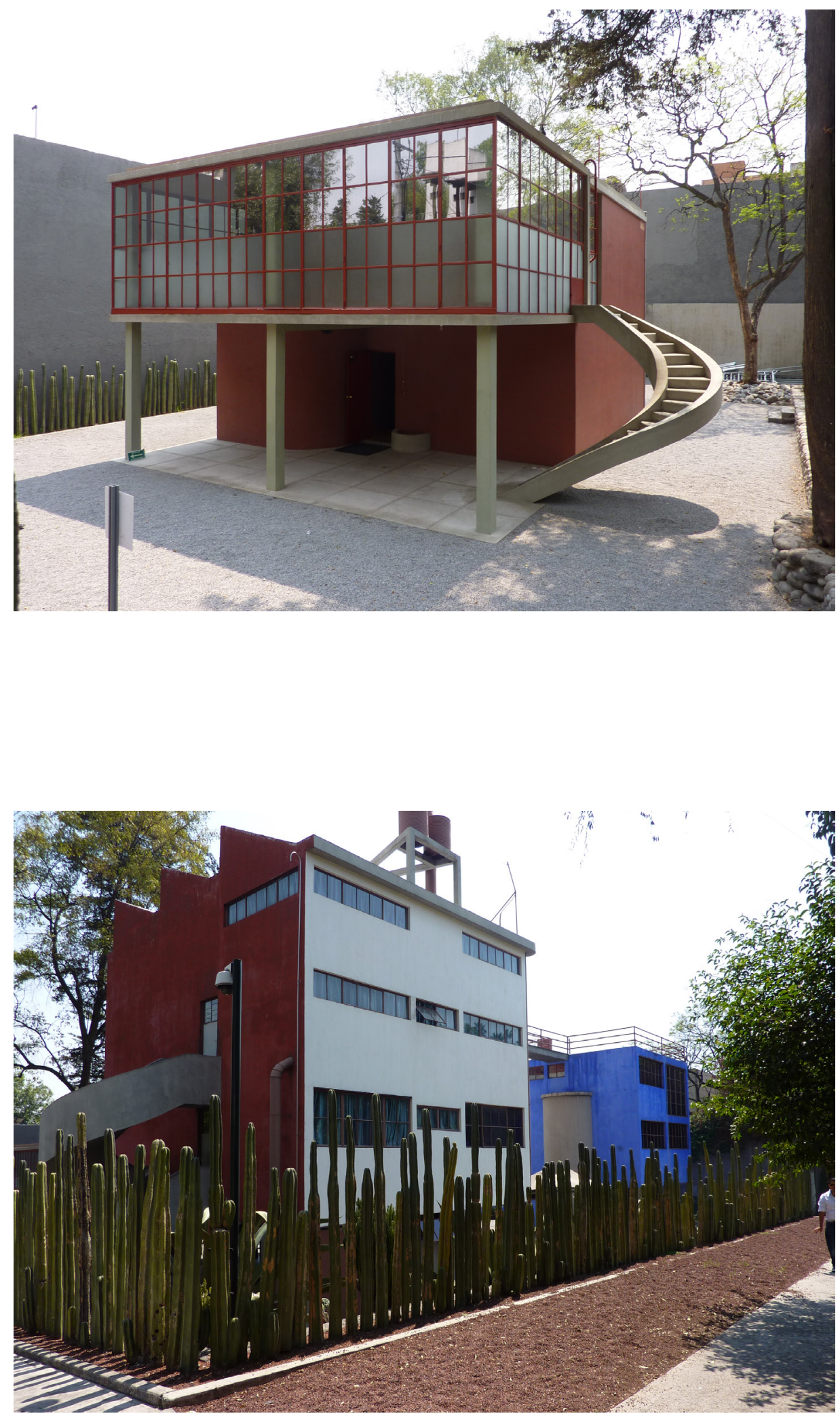

Rev. CPC, São Paulo, n.22 especial, p.41-61, abr. 2017. 
FIGURA 12

Luis Barragán, Casa González Luna, Guadalajara. Foto: Louise Noelle.

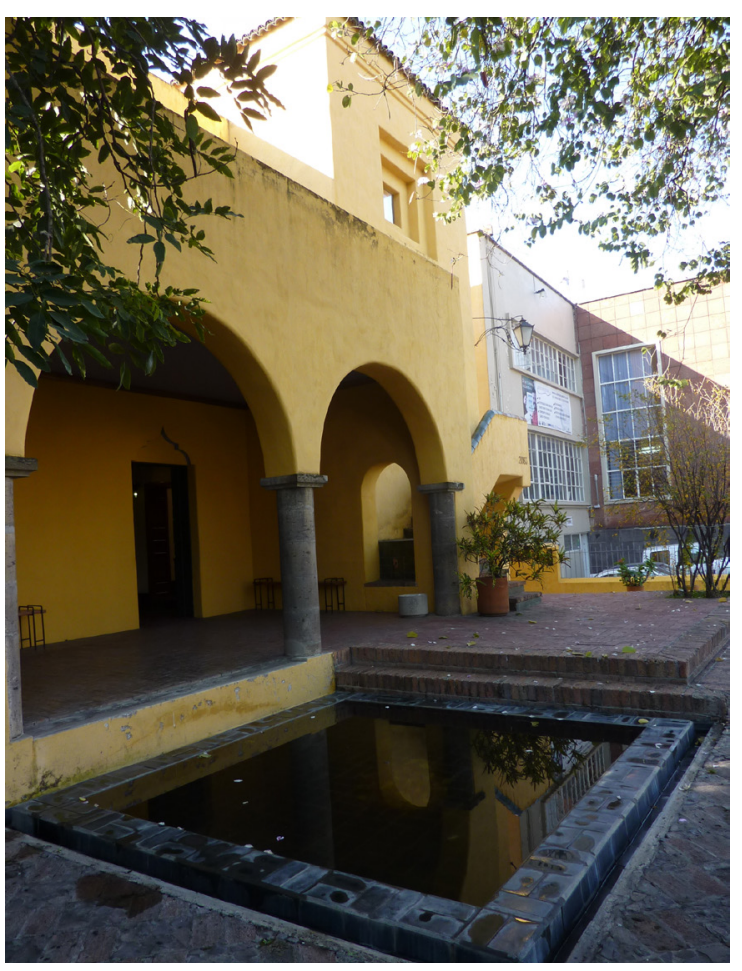

FIGURA 13

Enrique del Moral, Casa Yturbe, Acapulco, México. Muebles Clara Porset. Foto: Guillermo Zamora, archivo Louise

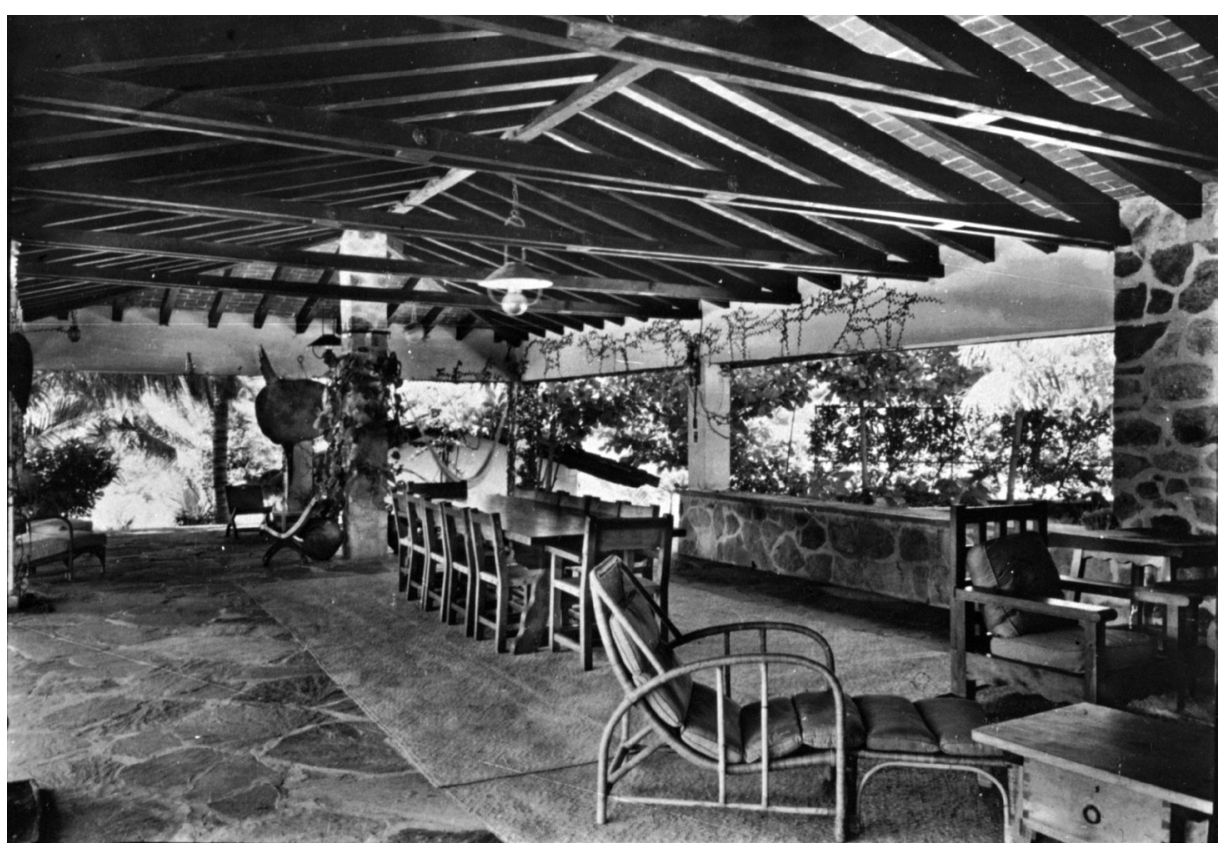


grandes paisajistas, como Burle Marx y Barragán, pero también se deben tomar en cuenta otros diseñadores; se trata de propuestas que recogen el sentido de lo local, de forma apasionada (NOELLE, 2004), para ofrecer respuestas adecuadas al entorno y el clima. Del mismo modo, la condición experimental de las residencias, encauzó a los arquitectos a acercarse al diseño de un mobiliario que fuese apropiado a los espacios habitables, ya sea en lo personal o de la mano de algún diseñador industrial; el ejemplo del trabajo de Charlotte Periand y Jean Prouvé para Le Corbusier, o Margaret Shütte-Lihotzky para el Bauhaus, tiene un símil en Clara Porset trabajando para buen número de arquitectos mexicanos (NOELLE, 2012).

\section{LEGISLACIÓN}

Frente a esta riqueza arquitectónica y artística a lo ancho del territorio latinoamericano, resulta importante analizar de forma paralela los diversos lineamientos internacionales que atañen a su conservación; sabemos que cada país tiene diversos grados en su legislación, en cuanto a la protección
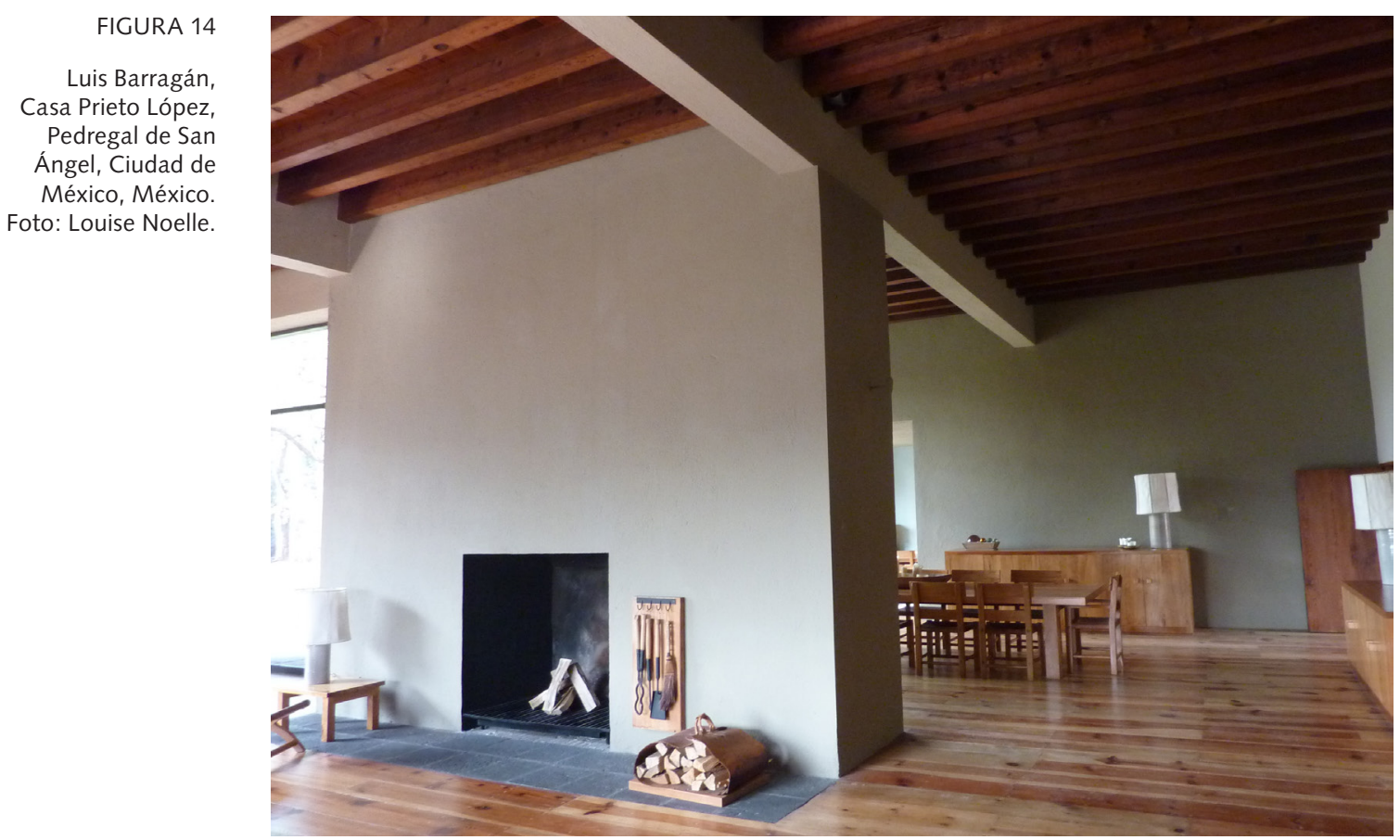
para las obras del siglo XX, aunque también estamos conscientes que las casas se encuentran siempre en mayor indefensión.

En cuanto a los documentos internacionales, emanados de organismos como la UNESCO o ICOMOS, si bien son esclarecedores y de gran yuda, también se puede considerar que uno de los problemas de base proviene de la propia Carta de Venecia ${ }^{8}$; ciertamente, en cuanto a defensa y protección habla de "Monumentos", siendo que la mayoría de las casas no se pueden considerar de esta forma. En efecto, en el Artículo 4 se enuncia que "La conservación de monumentos implica primeramente la constancia en su mantenimiento.", agregando en el Artículo 5 que "La conservación de monumentos siempre resulta favorecida por su dedicación a una función útil a la sociedad; tal dedicación es por supuesto deseable pero no puede alterar la ordenación o decoración de los edificios." Dichas consideraciones son adecuadas y se deben de mantener, a pesar de que se trate de obras que difícilmente se pueden definir como monumentales. Por otra parte, en el Documento de Nara sobre la Autenticidad ${ }^{9}$, descubrimos una referencia específica a la Diversidad Cultural y a la Diversidad del Patrimonio, señalando que son "una fuente irreemplazable de riqueza espiritual e intelectual para toda la humanidad." Asimismo, encontramos que esta herencia cultural es el patrimonio de todos, por lo que debe conservar su carácter ya que "el reconocimiento de la autenticidad juega un papel importante en todos los estudios científicos del patrimonio cultural, en los planes de conservación y restauración." Para efectos de la conservación de residencias, estas propuestas son de gran utilidad.

\section{A MANERA DE CONCLUSIÓN}

En una conferencia de 1957, Alvar Aalto decía "La arquitectura tiene una segunda intención... la idea de crear el paraíso. Esa es la propuesta de nuestras casas. ${ }^{\prime \prime 0}$ De cierta forma, esta frase define las diversas propuestas, que a los largo del siglo pasado realizaron los arquitectos que ratificaron

\footnotetext{
8. Carta de Venecia, 1964. Consultada en: <www.icomos.org $>$.

9. Documento de Nara sobre la autenticidad, 1994. Consultado en: <http://www.icomoscr.org $>$. 10. Alvar Aalto, Villa Mairea, Helsinki, Alvar Aalto Foundation, 1998. "Architecture has an ulterior motive... the thought of creation paradise. It is the only purpose of our houses", tomado de su conferencia dictada en Malmö en 1957, “The Architects Conception for Paradise”. P. 2.
} 
la modernidad. Por ello, la presente revisión de algunos ejemplos específicos, permite adentrase en una valoración del genero habitacional en el Movimiento Moderno; asimismo, se puede apreciar como el análisis de las diversas formas de conservación de estos espacios y su posible utilización actual, debe trascender la simple descripción del fenómeno físico para entrever diversos pliegues de la compleja situación de estas edificaciones.

Cabe agregar que los desarrollos formales o estructurales de las casas, así como el empleo de materiales industriales juegan un papel fundamental en el reconocimiento que han logrado ciertas obras, así como la habilidad o dificultad para preservarlos; además, en la mayoría de los casos, la riqueza de la composición y la libertad en el diseño produjeron construcciones que combinaron con éxito materiales tradicionales con elementos novedosos. Este acercamiento a técnicas y materias primas a la vez innovadoras y complejas de reproducir y conservar, ha resultado en una complicada labor de restauración a la vuelta de los años.

Aún más, estas edificaciones privadas fueron sometidas, en algunos casos, al desafío de adaptarse tanto a entornos geográficos inusitados como a climas extremos, buscando una congruencia ecológica, para el bienestar de sus habitantes. Sin embargo, los medios actuales que promueven un mayor confort, no siempre son instalados de forma acertada; es el caso de maquinarias para aire acondicionado o calefacción, al igual que techumbres o nuevos materiales aislantes, así como carpinterías de aluminio para ventanas que fueron originalmente de fierro, así como vidrios de colores y calidad diversa a la original; una larga lista de modificaciones y materiales diversos dificulta así esta tarea de adaptación frente a los requerimientos de la conservación. A esto se agrega, por el cambio de uso, la pérdida del mobiliario original y hasta de obras de arte, al igual que el descuido de las áreas ajardinadas. Sin embargo, es imposible pensar que las casas del Movimiento Moderno, que fueron diseñadas y construidas hace varias décadas, se deben conservar integra y totalmente, y convertirlas todas en museos; resulta entonces importante valorar cada caso, para llegar a las mejores soluciones de conservación y re-uso.Por ello me permito concluir con Sir Winston Churchill "De una cosa estoy seguro, si iniciamos una pelea del pasado y el presente, nos encontraremos con que hemos perdido el futuro." (BANDARIN; VON OERS, 2014, p. 33) 


\section{REFERENCIAS}

Aalto, Alvar, Villa Mairea, Helsinki, Alvar Aalto Foundation, 1998.

Arai, Alberto T., La casa mexicana. Ideas sobre la habitación popular urbana, $\mathrm{N}^{\circ}$ 2, México, SAM, s/f.

Ayala Alonso, Enrique, La idea de habitar: La Ciudad de México y sus casa 1750-190o, México, UAM-X, 2009.

Bandarin, Franceso y Ron van Oers, El paisaje urbano histórico. La gestión del patrimonio en un siglo urbano, Madrid, Abada Editores, 2014.

Curtis, William, "The General and the Local. Enrique del Moral's Own House”, Modernity and the Architecture of Mexico, Edward R. Burian Editor, Texas University Press, 1997.

García Moreno, Beatriz, De la casa patriarcal a la casa nuclear, Bogotá, Pontificia Universidad Javeriana, 1995.

Aizpuru ,Pilar Gonzalbo, Historia de la vida cotidiana en México, Vol. I a V, México, El Colegio de México-FCE, 2006.

Lapuerta, José María, “Diez experiencias modernas", A\&V, N 132 "Casas de Maestros”, Madrid, Arquitectura Viva, 2009.

Lefas, Pavlos, Dweling and Architecture. From Heidegger to Koolhas, Berlín, Jovis, 2009.

Milan Acayaba, Marlene, Residências em Sao Paulo: 1947-1975, Sao Paulo, Romano Guerra Editora, 2011.

Moral, Enrique del, Defensa y conservación de las ciudades y Conjuntos urbanos monumentales, Academia de Artes, México, 1980. P. 7.

“Arquitectura en Acapulco", Arquitectura/México, No 46, México, 1954.

“Lo general y lo local”, Espacios, No. 2, México, 1948.

__- “Modernidad contra tradición, integración”, Arquitectura/México, No. 45, México, 1954.

Noelle, Louise, Luis Barragán, búsqueda y creatividad, UNAM, México, 1996.

Noelle, Louise, Enrique del Moral. Vida y obra, UNAM, México, 2004.

Noelle, Louise, “Roberto Burle Marx y Luis Barragán: un acercamiento apasionado al ámbito latinoamericano", Estética del Paisaje en las Américas, México, IIE-UNAM, 2016.

Noelle, Louise, "Clara Porset, a Modern Designer for Mexico", Docomomo Journal, No 46, Barcelona, 2012.

O’Gorman, Juan, "Un ensayo de arquitectura orgánica”, Arquitectura/México, No. 112, México, 1976.

Pasados Presentes. La vivienda en Colombia, Editor Alberto Saldarriaga Roa, Bogotá, Pontificia Universidad Javeriana, 2009. 
Clara Porset's Design. Creating a Modern Mexico, México, Museo Franz Meyer-UNAM, 2006.

Rykwert, Joseph, On Adams House in Paradise: the Idea of the Primitive Hut in Architectural History, Nueva York, MoMA, 1972.

Segre, Roberto. Casas brasileiras. Rio de Janeiro, Viana \& Mosley, 2010.

Documentos

Carta de Venecia, 1964. Consultada en: www.icomos.org

Documento de Nara sobre la autenticidad, 1994. Consultado en: http://www.icomoscr.org 